\title{
Hiperoxaluria primaria con pancitopenia: a propósito de un caso.
}

\author{
Primary hyperoxaluria and pancitopenia: A case report.
}

\author{
BRAVO ZUÑIGA Jessica ${ }^{1}$, CIEZA TERRONES MichaeP, LOZA MUNÁRRIZ Reyner ${ }^{3}$,FERRUFINO LLACH \\ Juan Carlos ${ }^{4}$, MAYO SIMON Nancy ${ }^{5}$.
}

\section{SUMMARY}

A 15-year-old boy with story of recurrent kidney stones which began since 2 years old. He developed progressive renal failure and for the past 3 years he had required hemodialysis. Six months ago he developed oligoarthritis and anemia. On physical examination there was hepatosplenomegaly with lymphadenopathy. Laboratory studies showed pancytopenia, hemoglobin level of $7.3 \mathrm{gr} / \mathrm{dL}$, white blood cell count of $2,600 /$ $\mathrm{mm}^{3}$, and platelet count of $123,000 / \mathrm{mm}^{3}$. Values of serum GOT, GPT and bilirubin were normal. Ultrasound scan of abdomen revealed atrophic, heavily calcified kidneys and $X$ rays showed nephrocalcinosis. Bone biopsy revealed extensive crystal deposition arranged in a radial pattern, with almost complete obliteration of hematopoietic cells with variable number of multinucleated cells and moderate fibrosis. Bone marrow aspirate did not show any calcium oxalate crystals. We review primary hyperoxaluria and underscore the importance of recognizing the disease as cause of renal failure, in a patient with clinical history of renal stones and nephrocalcinosis. (Rev Med Hered 2004;16:148-156).

KEY WORDS: Hyperoxaluria, oxalosis, pancitopenia, nephrocalcinosis, renal stones.

\section{RESUMEN}

Se presenta el caso de un varón, de 15 años de edad, con diagnóstico de litiasis renal desde la infancia que evolucionó a Insuficiencia Renal Crónica, requiriendo hemodiálisis. Seis meses antes del reporte se agregan dolores articulares, con signos flogósicos en rodilla derecha, compromiso progresivo del estado general, pérdida de peso y anemia. Al examen físico se encuentra a un paciente emaciado, pálido, con múltiples adenopatías cervicales, y presencia de hepato-esplenomegalia. Se realizan exámenes evidenciándose: pancitopenia, con mayor compromiso de la serie roja (hemoglobina $7,3 \mathrm{mg} / \mathrm{dL}$, leucocitos $2600 / \mu \mathrm{L}$, y plaquetas $123000 / \mu \mathrm{L}$.). Los valores de transaminasas y bilirrubinas fueron normales así como los dosajes de Fierro, Transferrina, Ácido Fólico y Vitamina B12. La ecografía abdominal revela riñones calcificados y atróficos y los $\mathrm{Rx}$ de abdómen demuestran nefrocalcinosis y litiasis renal. La biopsia de medula ósea evidenció un extenso depósito de cristales de oxalato de calcio, dispuestos en forma radiada, con casi completa obliteración de la medula ósea con un número variable de células multinucleadas y fibrosis moderada. El aspirado de medula ósea no mostró cristales de oxalato de calcio. Este reporte hace una

\footnotetext{
$1 \quad$ Médico Nefrólogo, ex Médico residente Servicio de Nefrología Hospital Nacional Cayetano Heredia. Facultad de Medicina Universidad Peruana Cayetano Heredia.

2 Médico Residente, Servicio Nefrología, Hospital Nacional Cayetano Heredia, Facultad de Medicina Universidad Peruana Cayetano Heredia.

3 Médico Nefrólogo Pediatra, Hospital Nacional Cayetano Heredia.

4 Jefe del Departamento de Patología, Hospital Nacional Cayetano Heredia.

5 Médico asistente del Departamento de Patología, Hospital Nacional Cayetano Heredia.
} 
revisión sobre hiperoxaluria primaria, y resalta la importancia de reconocer la enfermedad como causa de falla renal en un paciente con historia clínica de litiasis renal y nefrocalcinosis. (Rev Med Hered 2004;16:148-156).

PALABRAS CLAVE: Hiperoxaluria, oxalosis, pancitopenia, nefrocalcinosis, litiasis renal.

\section{INTRODUCCIÓN}

La hiperoxaluria primaria es un desorden genético raro de carácter autosómico recesivo causado por la deficiencia de una enzima hepática, la cual condiciona un incremento en la producción de ácido oxálico que conduce a hiperoxalemia y a depósito de cristales de oxalato de calcio en diferentes órganos especialmente en el riñón donde desarrolla nefrocalcinosis y nefrolitiasis llevando a falla renal crónica, cuadro sistémico al cual se ha denominado oxalosis.

El pronóstico de la enfermedad es malo ya que la mitad de los niños evoluciona a falla renal terminal a la edad de 10 años, requiriendo un trasplante combinado hígado-riñón, de no realizarse, el paciente fallece por falla multiorgánica (1).

La incidencia de urolitiasis en la niñez es 1,5 casos por millón de habitantes y 1 niño de 5 y 15 millones entre 0 a 15 años, presentar falla renal debido a hiperoxaluria $(2,3)$.

Presentamos el caso de un niño en terapia de hemodiálisis crónica, con un cuadro de oxalosis sistémica, primer caso descrito en nuestro país.

\section{Caso Clínico}

Paciente varón de 15 años, natural y procedente de San Martín, con historia de eliminación de cálculos por la orina desde el primer año de vida, requiriendo extracción quirúrgica a la edad de 8 años. Fue diagnosticado de insuficiencia renal crónica terminal secundario a uropatía obstructiva a los 12 años, ingresando a terapia de hemodiálisis crónica.

El paciente se mantuvo estable hasta tres años después de iniciar diálisis, momento en el cual presenta disminución del hematocrito a pesar del uso de eritropoyetina subcutánea a dosis adecuada y cursar con niveles séricos de hierro, vitamina $\mathrm{B}_{12}$ y saturación de transferrina en rangos de normales. Así mismo se observa, pérdida de peso, astenia, adinamia y al examen físico adenopatías cervicales e inguinales múltiples y hepatoesplenomegalia.

En la evolución se agrega dolor, aumento de volumen e impotencia funcional de la rodilla por lo que es hospitalizado. Los estudios de liquido articular mostraron exudado y se aisló Staphylococcus aureus, recibiendo cobertura antibiótica con mejoría parcial.

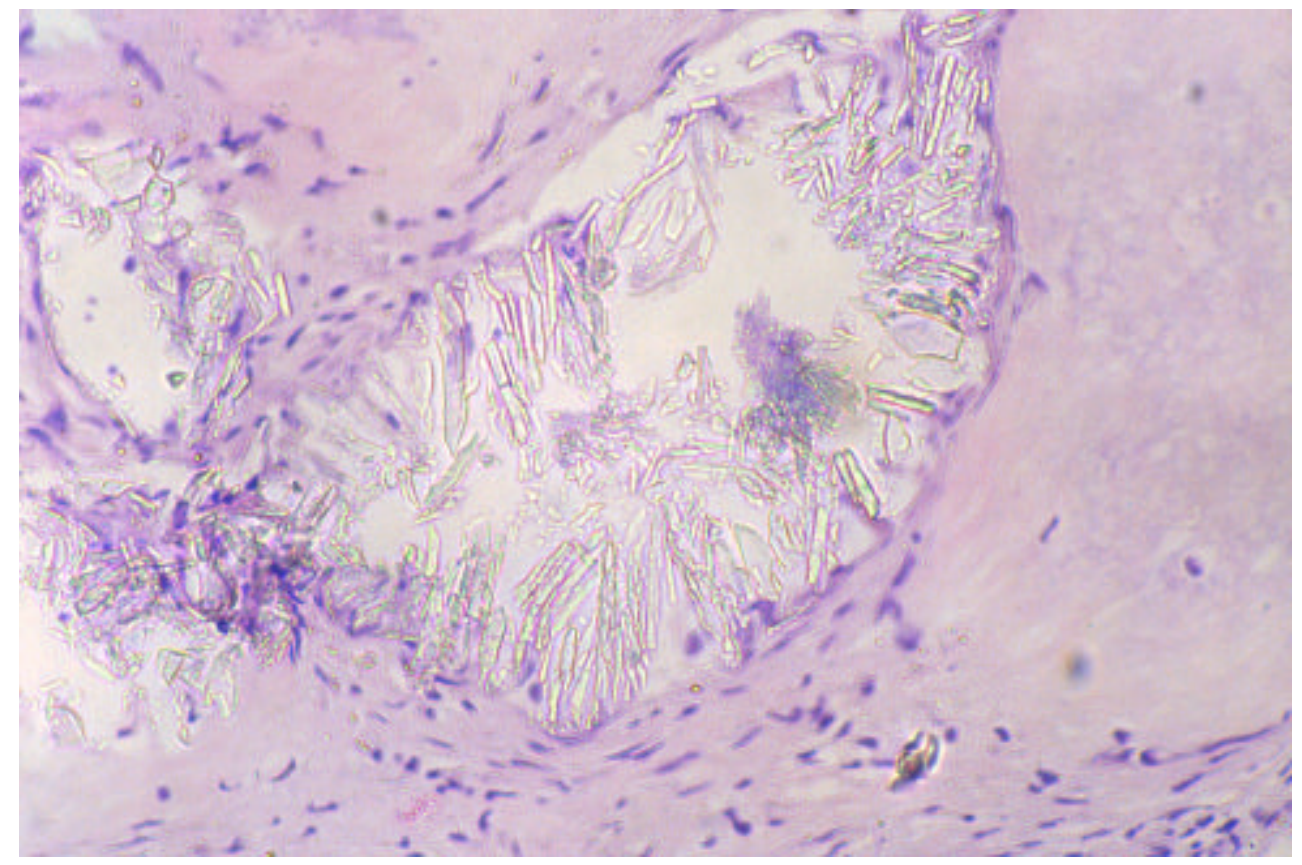

Figura $\mathrm{N}^{\circ}{ }^{1}$. Biopsia de hueso iliaco muestra un reemplazo casi total de la médula ósea por cristales de oxalato de calcio. 


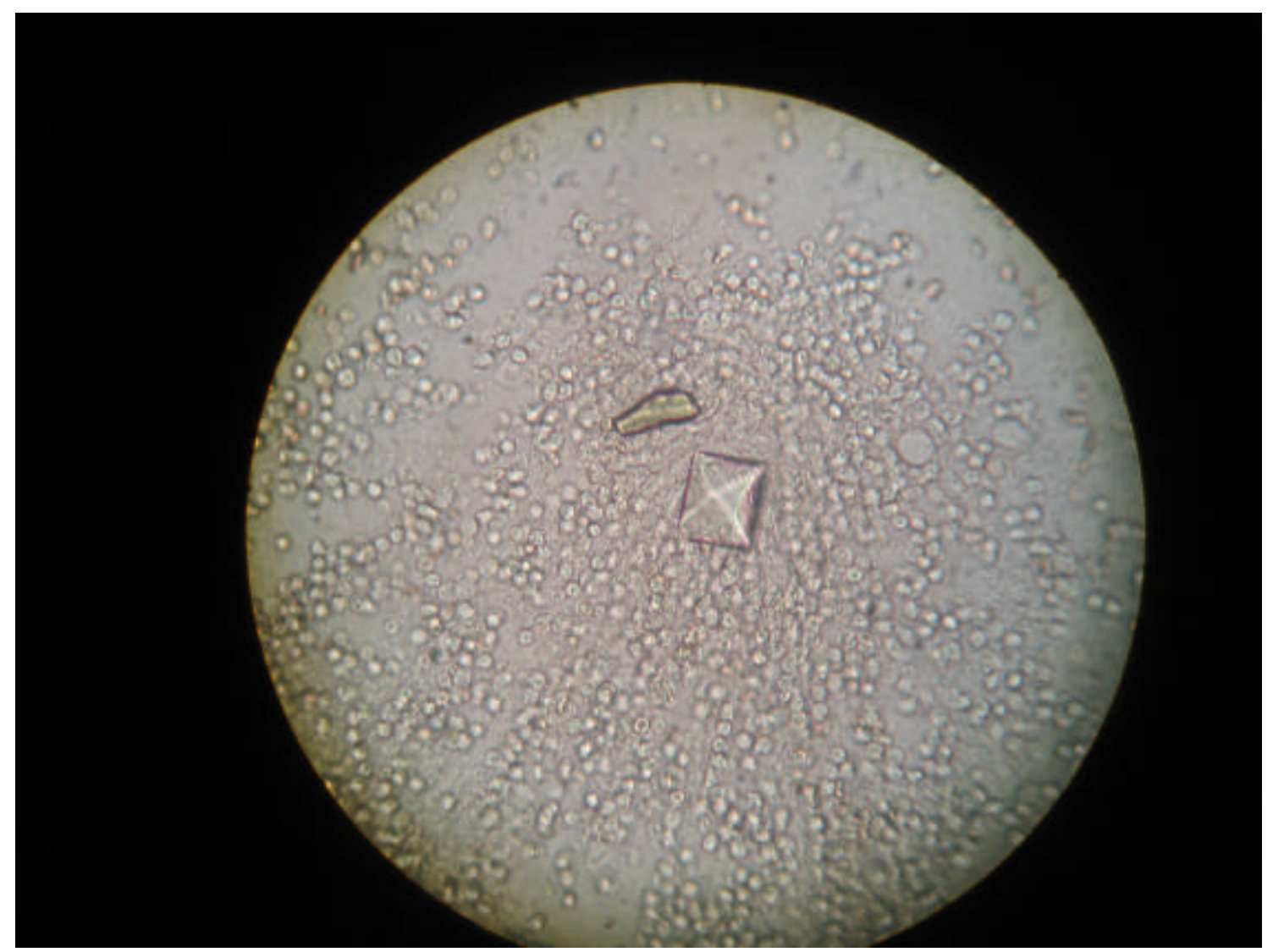

Figura $\mathrm{N}^{\circ}$ 2. Examen de orina mostró presencia de cristales de oxalato de calcio.

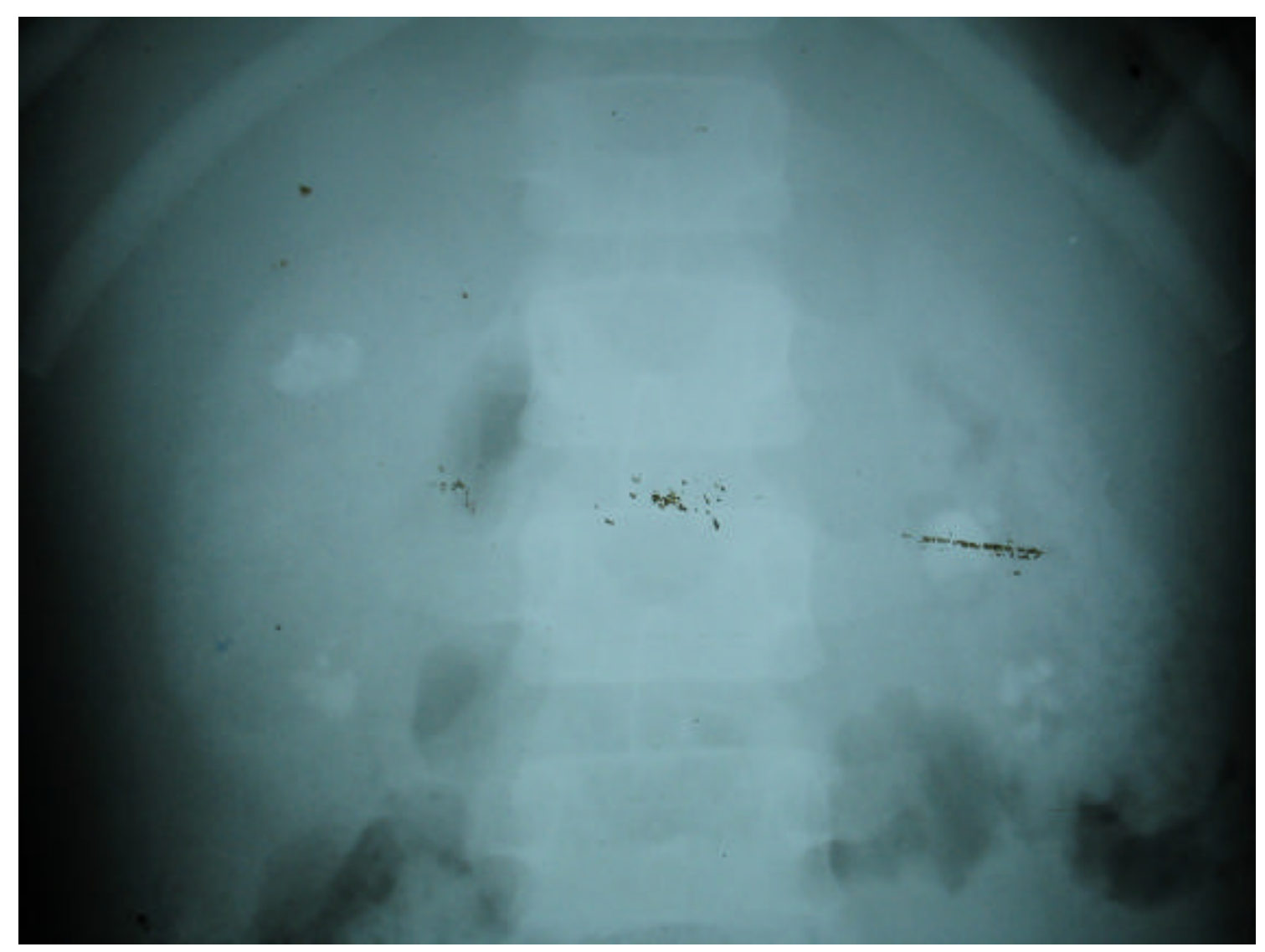

Figura $\mathrm{N}^{\circ}$ 3. Radiografía simple de abdomen muestra imágenes compatible con litiasis y nefrocalcinosis. 
Para descartar la posibilidad de tuberculosis se realizó artroscopía con biopsia de sinovia y biopsia de adenopatía cervical las que fueron informadas como negativas para BK tanto en frotis como en cultivo. Es dado de alta con el diagnóstico de Monoartritis infecciosa probablemente relacionada a infección de fístula arteriovenosa.

Además se encontró disminución de las otras series sanguíneas con pancitopenia, con mayor compromiso de la serie roja (hemoglobina $7,3 \mathrm{mg} / \mathrm{dL}$, leucocitos $2600 / \mu \mathrm{L}$, y plaquetas de $123000 / \mu \mathrm{L}$.$) , por lo que se le$ realizó aspirado de medula ósea y biopsia de hueso. El aspirado de médula ósea no fue contributorio, por no contener espículas, pero la biopsia de hueso iliaco mostró un reemplazo casi total de la médula ósea por cristales de oxalato de calcio, los que en el tejido tenían disposición de forma radial, birrefringentes rodeados y parcialmente fagocitados por células epitelioides y gigantes multinucleadas (Figura $\mathrm{N}^{\circ} 1$ ).

El examen de orina mostró presencia de cristales de oxalato de calcio (Figura $\mathrm{N}^{\circ}$ 2), la radiografía simple de abdomen imágenes compatibles con litiasis y nefrocalcinosis (Figura $\mathrm{N}^{\circ} 3$ ), y en el estudio de ecocardiografía imágenes hiperrefringentes en el septum interventricular (Figura $\mathrm{N}^{\circ} 4$ ).

La biopsia de ganglio mostró hiperplasia folicular con extensas áreas de macrófagos y pigmento hemático, compatible con un síndrome hemofagocítico (Figura $\mathrm{N}^{\circ}$ 5), el cual es un desorden de la regulación inmune, caracterizado por una amplia proliferación e infiltración multisistémica de histiocitos no malignos, que provocan una descontrolada hemofagocitosis en la medula y el RES, que se asocia a una serie de enfermedades crónicas.

Con el antecedente epidemiológico, la evolución clínica y de laboratorio se confirmaría el diagnostico de Oxalosis primaria sistémica tipo autosómica recesivo por la historia de consanguinidad de los padres (primos).

\section{DISCUSIÓN}

Un paciente con antecedentes de litiasis renal, cristales de oxalato de calcio en orina y en médula ósea, nos lleva a concluir que presenta un cuadro de oxalosis (compromiso sistémico por depósito de oxalato de calcio) el mismo que debe ser condicionado por un cuadro de hiperoxaluria (Gráfico $\mathrm{N}^{\circ} 1$ ).

La hiperoxaluria primaria es una enfermedad autosómica recesiva que se caracteriza por un defecto en el metabolismo debido a un déficit de la enzima hepática peroxisomal alanina glioxilato aminotransferasa (AGT) (4), que determina un incremento en la excreción urinaria de oxalato y glicolato en cuyo caso se denomina Hiperoxaluria tipo 1 (PH1), o por la deficiencia de una enzima citosólica con actividad de glioxilato reductasa, hidroxipiruvato reductasa, y d-glicerato deshidrogenasa caracterizándose en este caso por excreción urinaria elevada de oxalato de calcio y ácido L glicérido, tomando la denominación de Hiperoxaluria tipo 2: PH2 $(5,6)$.

La hiperoxaluria tipo 1, es el tipo más común fue descrita por primera vez en 1952 por Chau y Donohue (6), y recién en 1986 se localizó el defecto en los peroxisomas hepáticos (4).

El gen que codifica para AGT, es decir, el AGxT esta localizado en el cromosoma 2q37.3, y debido a que presenta una variedad de mutaciones, tiene una considerable heterogeneidad molecular, encontrándose pacientes heterocigotos y en poblaciones con alta tasa de consanguinidad, patrón homocigoto. Lo cual correlaciona con la historia de nuestro paciente. El $50 \%$ de los pacientes exhiben actividad catalítica de la AGT no detectable, y la otra mitad, actividad residual (7).

Como se conoce, la litogénesis ocurre cuando se altera el equilibrio entre promotores (oxalato) e inhibidores (citrato, magnesio y glicosaminoglicanos), en la hiperoxaluria la orina esta supersaturada con relación al oxalato de calcio $(8,9)$, y esto conduce a la formación de cálculos o nefrocalcinosis $(10,11)$.

Así, mayor cantidad de oxalato es filtrado conduciendo a una extrema concentración en las células tubulares proximales, lo cual causa un daño tóxico directo, retardando su crecimiento y disminuyendo su tiempo de vida media (12).

Tanto los niveles séricos de oxalato como la presencia de insuficiencia renal pueden ejercer efectos tóxicos en otros órganos. El depósito de cristales de oxalato de calcio se inicia en forma temprana, y los pacientes tienen riesgo de depósitos sistémicos antes de llegar a falla renal crónica.

El diagnóstico se puede hacer midiendo la excreción de oxalato urinario, siendo alto cuando los niveles son mayores que $2 \mathrm{mmol} / 24 \mathrm{hs} / 1,73 \mathrm{~m}^{2}$ (normal $<0,5 \mathrm{mmol} /$ $\left.24 \mathrm{hs} / 1,73 \mathrm{~m}^{2}\right)$; sin embargo, deben tomarse en cuenta una colección adecuada de orina, pues se requiere la acidificación con $\mathrm{pH}<7,2$, para prevenir depósitos de Oxalato de Calcio insolubles, convertir la excreción de oxalato a la superficie corporal del paciente, 


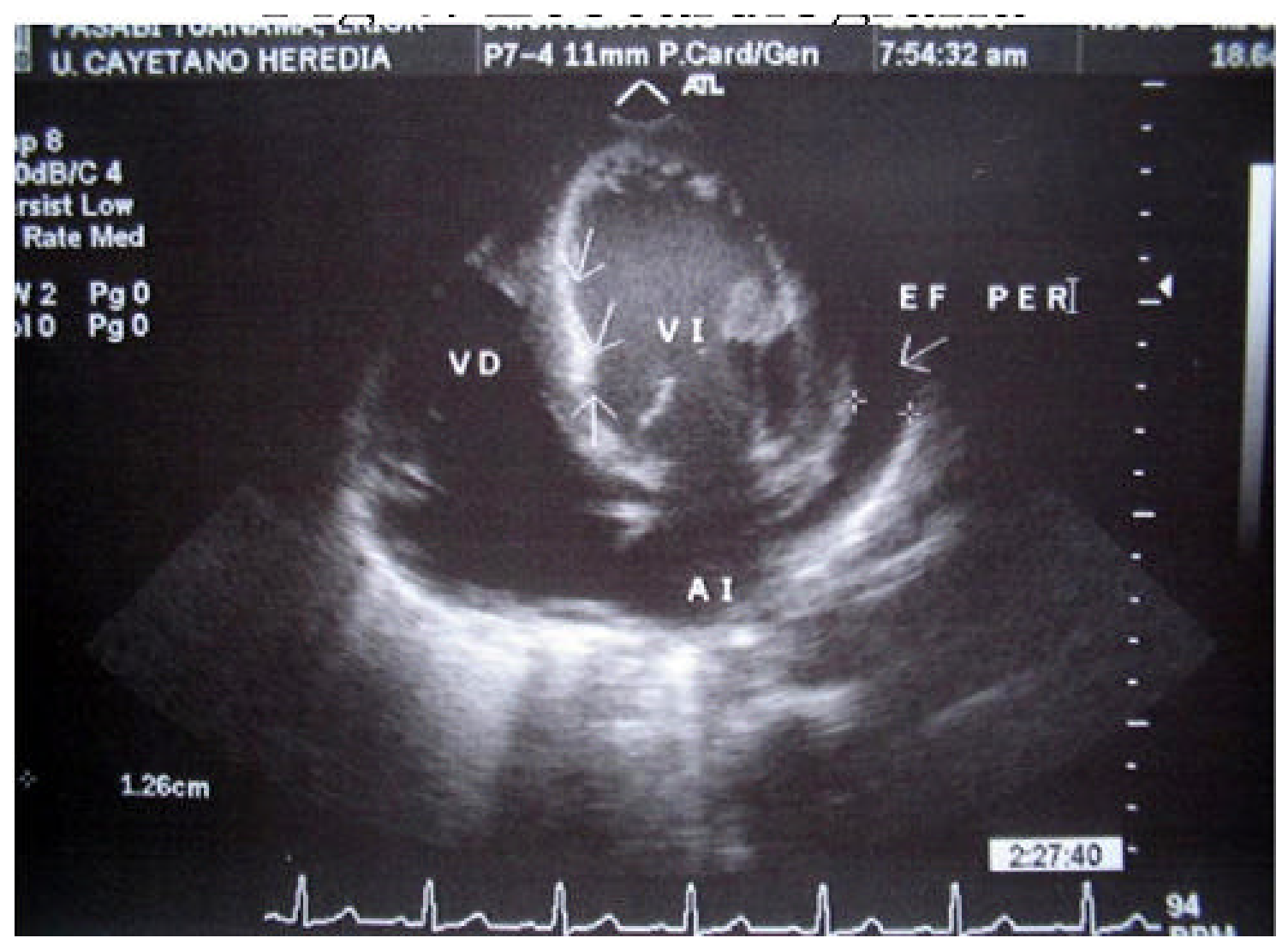

Figura $N^{\circ}$ 4. Estudio de ecocardiografía muestra imágenes hiperrefringentes en el septum interventricular.

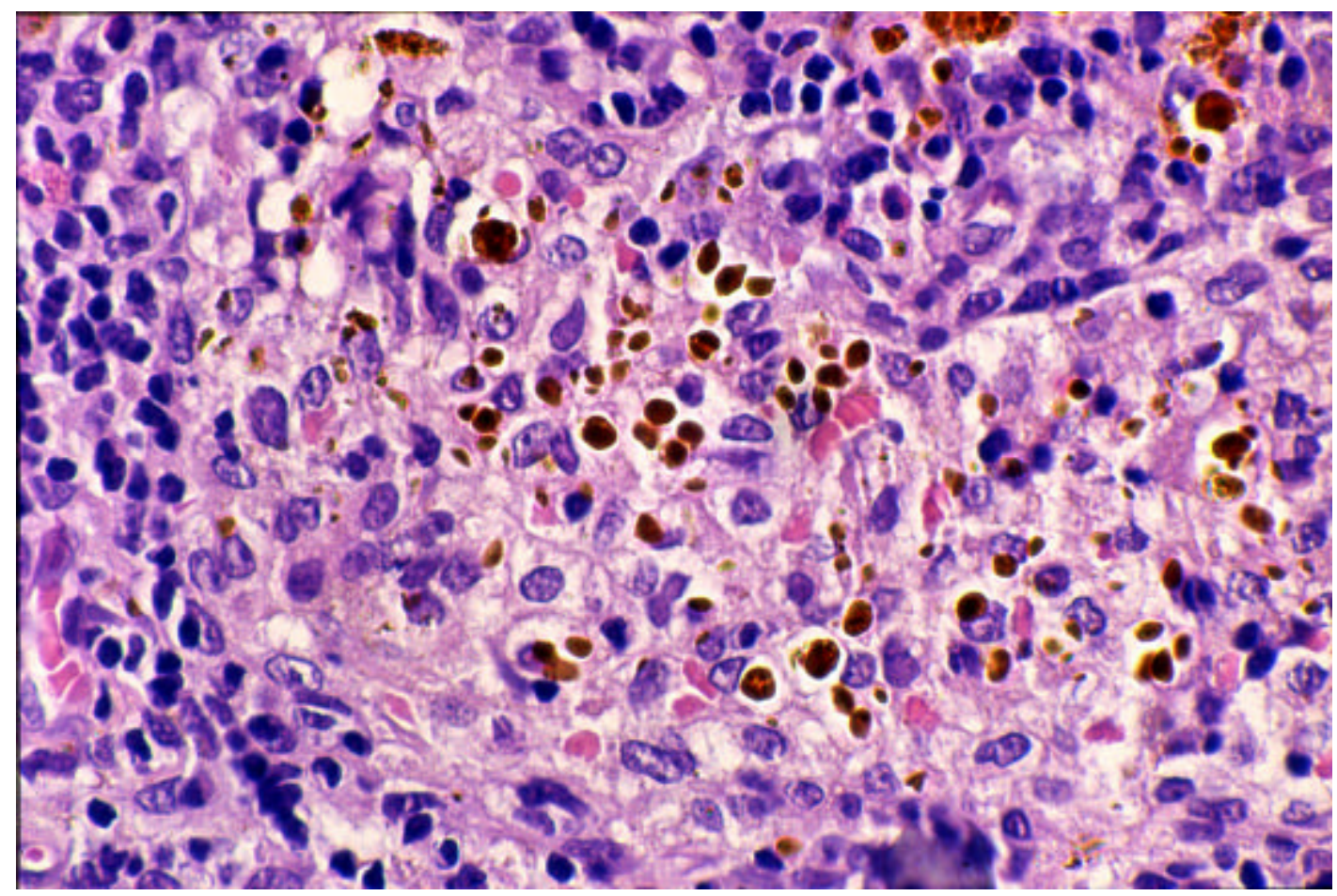

Figura $\mathrm{N}^{\circ}$ 5. Descontrolada hemofagocitosis en la medula y el RES, que se asocia a una serie de enfermedades crónicas. 
Gráfico $\mathrm{N}^{\circ} 1$. Cuadro de oxalosis (compromisos sistémicos por deposito de oxalato de calcio).

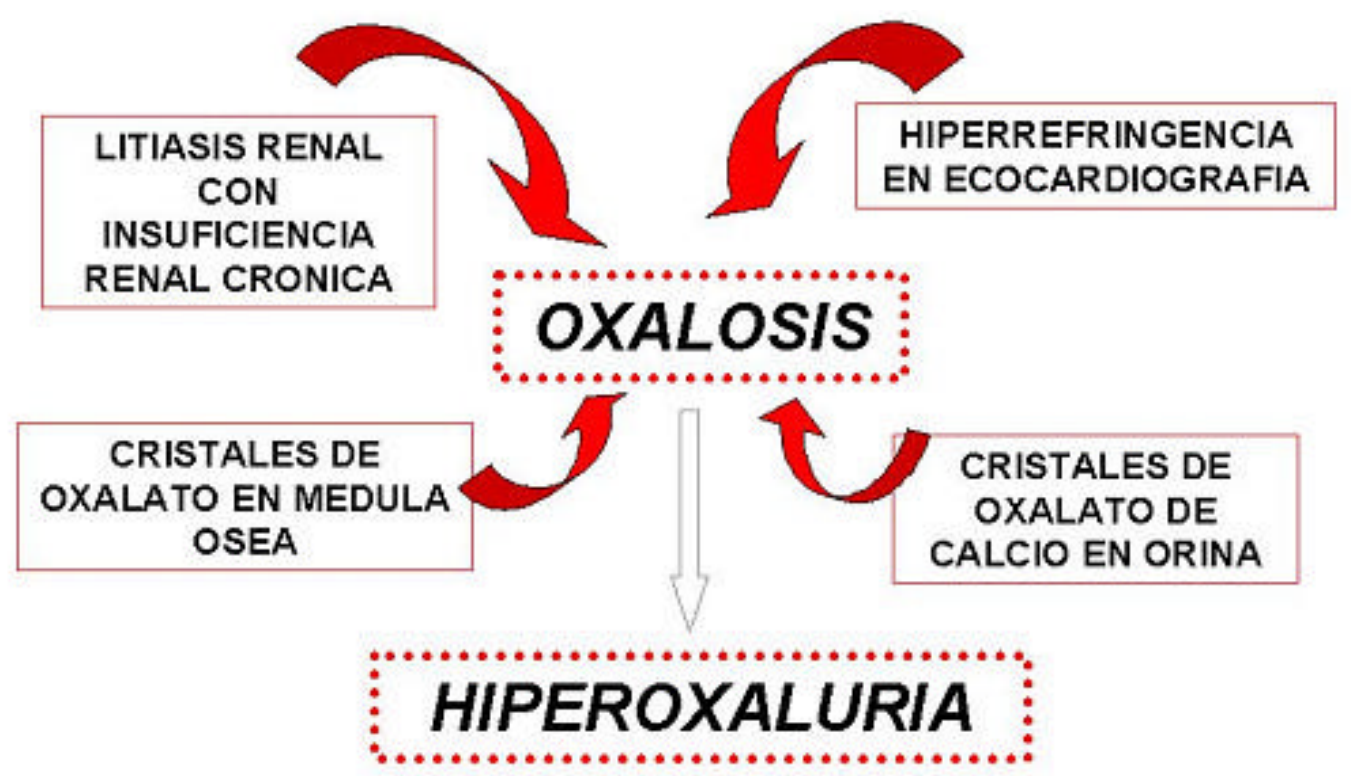

especialmente en niños y considerar la reducción de la excreción urinaria en pacientes con Insuficiencia renal. Los niveles de glicolato solo están elevados en $2 / 3$ de los pacientes por lo cual el hallazgo de un valor normal no excluye el diagnóstico (13).

Se puede realizar, además la medición de oxalato plasmático recordando que en pacientes con función renal normal, se alcanzan valores de >6,3uM, y en insuficiencia renal $>80 \mathrm{uM}$.

El diagnóstico definitivo se hará midiendo la actividad de AGT e inmunoreactividad en tejido hepático (14).

Como los pacientes tienen frecuentemente componente heterocigoto, y la mutación a menudo permanece no identificable, el análisis de DNA es un examen poco práctico, sin embargo, el screening en poblaciones con alto riesgo de componente homocigoto podría ser útil. El diagnóstico prenatal puede realizarse por biopsia de las vellosidades coriónicas (14).

Otra medida a tomar debería ser el análisis de cálculos, pues el componente principal consiste casi exclusivamente de oxalato de calcio monohidrato: subtipo 1c, que es patognomónico $(15,16)$. Las biopsias óseas en pacientes con falla renal muestran la presencia de los cristales birrefringentes, y el examen ocular es también una prueba diagnóstica importante.

Acerca de las manifestaciones clínicas la nefrolitiasis recurrente y la nefrocalcinosis son los síntomas principales, la combinación de ambas conduce a la pérdida progresiva de la función renal. La mitad de los pacientes exhiben síntomas antes de los 5 años, sin embargo, la severidad clínica no correlaciona con la mutación o el grado de actividad funcional de la AGT, mas bien se observa una gran heterogeneidad clínica, bioquímica y genética, así algunos pacientes pueden llegar a falla renal terminal y otros a eliminación de algunos cristales en la orina a edades similares $(17,18,19)$, aun miembros de la misma familia y con la misma mutación pueden exhibir diferentes fenotipos clínicos.

Existe también una variante maligna en la que alteración ocurre muy temprano, menos de cuatro meses, y los infantes progresan rápidamente a falla renal terminal, y nefrocalcinosis pero sin cálculos (20).

La oxalosis sistémica se dará cuando se alcance el punto crítico de saturación del oxalato plasmático (niveles plasmáticos $>30 \mathrm{uM}$ ) es decir, en la insuficiencia renal temprana, los depósitos ocurren en una serie de órganos y tejidos excepto en el hígado, y llevan a consecuencias desastrosas.

Los huesos son el principal lugar de depósito, las lesiones son características tanto en los rayos X; bandas metafisiarias radiodensas, o apariencia de "hueso dentro del hueso", y desmineralización difusa con patrón trabecular, y el hallazgo histológico de "tofos" intra óseos de oxalato de calcio, y granulomas que reemplazan a la 
médula ósea. Las manifestaciones clínicas de la osteopatía por oxalato son dolor, fracturas espontáneas y anemia resistente a eritropoyetina, presentándose incluso en casos más severos pancitopenia $(21,22)$, como fue el caso de nuestro paciente.

Los depósitos de oxalato de calcio en la retina, pueden ser uno de los primeros signos obvios de oxalosis sistémica. Los hallazgos oculares incluyen: retinopatía cristalina, maculopatía geográfica negra, y atrofia óptica $(23,24)$.

Otros lugares de depósito pueden ser la media de las arterias, con subsiguiente isquemia y gangrena, el mecanismo presumido es el daño endotelial con espasmo luego de la cristalización in situ, el contacto del plasma con la superficie del cristal lleva a activación del complemento sérico, e incrementa las células endoteliales mediadas por neutrófilos y la liberación de radicales de oxigeno tóxicos (25). Otros órganos afectados son el sistema nervioso periférico, el miocardio, la glándula tiroides y la piel $(26,27,28)$.

Debido a que el cuadro clínico es larvado, la incidencia es fácilmente subestimada, los datos de Inglaterra, Suiza y Francia sugieren que 1/60,000 niños presentan esta patología, es mas frecuente en países como Túnez donde es la causa del $13 \%$ de IRC en niños, comparado con $<0,5 \%$ en Estados Unidos y Europa (29).

La oxalosis infantil tiene pobre pronóstico, $80 \%$ de los pacientes presenta falla renal crónica al momento del diagnóstico, la predicción del pronóstico para un paciente individual es difícil, los pacientes con TFG $>50 \mathrm{ml} / \mathrm{min}$ pueden permanecer estables por muchos años, pero pueden perder rápida e irreversiblemente la función residual, por episodios de deshidratación, obstrucción urinaria, y falta de tratamiento (30).

El tratamiento inicial puede ser conservador, en cuyo caso el objetivo es disminuir la producción e incrementar la solubilidad urinaria del oxalato de Calcio. El fosfato de piridoxina es un cofactor esencial para las aminotransferasas entre ellas la AGT, y las dosis farmacológicas $(5-20 \mathrm{mg} / \mathrm{kg} / \mathrm{d})$ son capaces de reducir hasta en un $30 \%$ de los pacientes los niveles de oxalato, los pacientes que más comúnmente responden son aquellos con actividad residual de AGT (31).

Para medir la respuesta a la piridoxina se requieren de al menos tres excreciones de oxalato urinario basales, aunque los efectos se evidencian a las dos semanas de tratamiento, se necesita por lo menos 3 meses para evaluar el mismo (32). Para el incremento de la solubilidad se requiere aumentar la ingesta de líquidos $(>2,5 \mathrm{~L} / \mathrm{m} 2 / \mathrm{d})$, además de drogas que incrementen la solubilidad del oxalato, como el ortofosfato $20-60 \mathrm{mg} / \mathrm{kg} / \mathrm{d}$, citrato de potasio o de sodio; $0,1-0,15 \mathrm{~g} / \mathrm{kg} / \mathrm{d}$ dividido en 4 a 6 dosis. Aunque la dieta contribuye poco en esta patología es necesario evitar alimentos con alto contenido de oxalato, como remolacha, espinacas, y té. La restricción de calcio y proteínas no se recomienda.

En cuanto al tratamiento en la insuficiencia renal crónica, debe recordarse que ni la hemodiálisis ni la diálisis peritoneal, son capaces de incrementar la excreción de oxalato de calcio, mas bien se acumula y se deposita en los tejidos, aunque el aclaramiento de oxalato es mayor en hemodiálisis $(120 \mathrm{ml} / \mathrm{min})$, con relación a diálisis peritoneal $(7 \mathrm{ml} / \mathrm{min})$, los valores de eliminación semanal son similares (33). Ni la combinación de las dos terapias ni el uso de dializadores de alto flujo, son capaces de prevenir la retención de oxalato. Así, la hemodiálisis intensa con sesiones diarias de 5-6 horas, será necesaria hasta someter al paciente a trasplante hepato- renal.

El trasplante renal aislado tiene un pobre pronóstico, con tasas de supervivencia del injerto a 3 años de $20 \%$ para injertos de cadáver y de $35 \%$ a los 10 años para donante vivo (34). Es mejor el trasplante simultáneo de hígado y riñón. La experiencia europea, que es la mayor, indica mejor pronóstico con una tasa de supervivencia a los 5 años de $80 \%$ para el injerto (35).

Los factores de riesgo específicos identificados para falla del injerto son: niños $<5$ años y tiempo en diálisis $>2$ años, se indica además que los pacientes con compromiso sistémico, no tienen buena respuesta al tratamiento (36). Así, lo más recomendable es un diagnóstico temprano y un tratamiento conservador agresivo, así como la decisión de un doble trasplante hígado riñón, en un paciente con poca respuesta al tratamiento médico, e idealmente aún sin compromiso sistémico.

El presente reporte debe servir para llamar la atención sobre una enfermedad hasta ahora desconocida en nuestro país, lo que ameritaría estudios epidemiológicos y de screenning para detectar este tipo de patología de tan pobre pronóstico que ataca a población infantil. 


\section{Correspondencia:}

Jessica Bravo Zuñiga

Servicio de Nefrologia

Hospital Nacional Cayetano Heredia

Av Honorio Delgado s/n San Martin de Porres

Lima Perú

Correo electrónico: ivobz@yahoo.es

\section{REFERENCIAS BIBLIOGRÁFICAS}

1. Gagnadoux MF, Lacaille F, et al. Long term results of liver-kidney transplantation in children with primary hyperoxaluria. Pediatr Nephrol 2001; 16(12): 946-50.

2. Latta K, Brodehl J. Primary hyperoxaluria Type I. Eur J Pediatr 1990; 149:512-522.

3. Escribano J, Rodriguez M, et al. Alteraciones metabólicas en la nefrolitiasis pediatrica. Acta Pediatr Esp 1994; 52: 279-288.

4. Danpure CJ, Jennings PR, Watts RWE. Enzymological diagnosis of primary hyperoxaluria type I by measurement of hepatic alanine:glyoxylate aminotransferase. Lancet 1987;1: 289-291.

5. Rumsby G, Cregeen DP. Identification and expression of a cDNA for human hydroxypyruvate/glyoxylate reductase. Biochim Biophys Acta 1999;1446: 383-388.

6. Basmaison O, Bozon D, Rolland MO, Koch-Nogueira PC, Dumontel Giafi CF, Rumsby G. Kinetic analysis and tissue distribution of human D-glycerate dehydrogenase/glyoxylate reductase and its relevance to the diagnosis of primary hyperoxaluria type 2. Ann Clin Biochem 1998;35: 104-109.

7. Chou L, Donohue W. Oxalosis: Possible "inborn error of metabolism" with nephrolithiasis and nephrocalcinosis due to calcium oxalate as the predominating features Pediatrics 1952;10 (6):660-666.

8. Takada Y, Kaneko N, Esumi H, Purdue E, Danpure J. Human peroxisomal L-alanine:glyoxylate aminotransferase: Evolutionary loss of a mitochondrial targeting signal by point mutation of the initiating codon. Biochem J 1990; 268: 517-520.

9. Cochat P. Primary hyperoxaluria. Kidney Int 1999;55: 2533-2547.

10. Leumann E, Hoppe B, Neuhaus T, Blau N. Efficacy of oral citrate administration in primary hyperoxaluria. Nephrol Dial Transplant 1995;10 (8): 14-16.

11. Lieske JC, Deganello S. Nucleation, adhesion, and internalization of calcium-containing urinary crystals by renal cells. J Am Soc Nephrol 1999; 10 (14): 422429.

12. Khan SR, Byer KJ, Thamilselvan S, Hackett RL, McCormack WT, Benson NA, Vaughn KL, Erdos G. Crystal-cell interaction and apoptosis in oxalateassociated injury of renal epithelial cells. J Am Soc Nephrol 1999;10 (14): 457-463.
13. Scheid C, Koul H, Hill WA, Luber-Narod J, Kennington L, Honeyman T, Jonassen J, Menon M. Oxalate toxicity in LLCPK1 cells: Role of free radicals. Kidney Int 1996;49: 413-419.

14. Hoppe B, Kemper MJ, Bökenkamp A, Portale AA, Cohn RA, Langman CB. Plasma calcium-oxalate supersaturation in children with primary hyperoxaluria and end-stage renal failure. Kidney Int 1999;56: 268 274.

15. Von Schnakenburg C, Weir T, Rumsby G. Linkage of microsatellites to the AGXT gene on chromosome 2q37.3 and their role in prenatal diagnosis of primary hyperoxaluria. Ann Hum Gen 1997;61: 365-368.

16. Daudon M, Estepa L, Lacour B, Jungers P: Unusual morphology of calcium oxalate calculi in primary hyperoxaluria. J Nephrol 1998;11 (1): 51-55.

17. Neuhaus TJ, Belzer T, Blau N, Hoppe B, Sidhu H, Leumann E. Urinary oxalate excretion in urolithiasis and nephrocalcinosis. Arch Dis Child 2000;82: 322326.

18. Hoppe B, Danpure CJ, Rumsby G, Fryer P, Jennings PR, Blau N, Schubiger G, Neuhaus T, Leumann E. A vertical (pseudodominant) pattern of inheritance in the autosomal recessive disease primary hyperoxaluria type I: Lack of relationship between genotype, enzymic phenotype and disease severity. Am J Kidney Dis 1997;29: 36-44.

19. Cochat P, Deloraine A, Rotily M, Olive F, Liponski I, Deries N. Epidemiology of primary hyperoxaluria type 1. Nephrol Dial Transplant 1995;10 (8): 3-7.

20. Kopp N, Leumann E. Changing pattern of primary hyperoxaluria in Switzerland. Nephrol Dial Transplant 1995; 10: 2224-2227.

21. Cochat P, Koch Nogueira PC, Mahmoud MA, Jamieson NV, Scheinman JI, Rolland MO. Primary hyperoxaluria in infants: Medical, ethical, and economic issues. J Pediatr 1999;135: 746-750.

22. Matthew J, Chi V. Pancytopenia Secondary to Oxalosis in a 23-Year-Old Woman. Blood 1998; 91 (11): 4394.

23. Halil O, Farringdon K. Oxalosis: an unusual cause of leucoerythroblastic anaemia. Br J Haematol 2003; 122(1):2.

24. Alcorn D, Fredrick D. Ophthalmic features of primary oxalosis after combined liver/kidney transplantation. Br J Ophthalmol 2000; 84(11):1326-1327.

25. Wells CG, Johnson RJ, Qingli L, Bunt-Milam AH, Kalina RE. Retinal oxalosis. A clinicopathologic report. Arch Ophthalmol 1989;107(11):1638-43.

26. Johnson J, Short A, Hutchison A. Small intestinal infarction: a fatal complication of systemic oxalosis. J Clin Pathol 2000; 53(9):720-721.

27. Takenaka H, Yasuno H, Fukuda T. Widespread cutaneous oxalosis in a patient with primary hyperoxaluria. Br J Dermatol 2003;149(5):1075.

28. Palka P, Duhig E, Carey L. Primary Oxalosis with cardiac involvement: Echocardiographic features of 
an unusual form of cardiomyopathy. Circulation 2001; 103(24):122-123.

29. Haqqani MT. Crystals in brain and meninges in primary hyperoxaluria and oxalosis. J Clin Pathol 1977;30:1618.

30. Leumann E, Hoppe B. What is new in primary hyperoxaluria?. Nephrol Dial Transplant 1999;14: 2556-2558.

31. Broyer M, Jouvet P, Niaudet P. Management of oxalosis. Kidney International 1996; 49 (53):S93-S98.

32. Yamauchi T, Quillard M, Takahashi S. Oxalate removal by daily dialysis in a patient with primary hyperoxaluria type 1. Nephrol Dial Transplant 2001; 16: 2407-2411.
33. Saborio P, Scheinman JI. Transplantation for primary hyperoxaluria in the United States. Kidney Int 1999;56: 1094-1100.

34. Watts RWE, Calne RY, Rolles K, Danpure CJ, Morgan SH. Successful treatment of primary hyperoxaluria type 1 by combined hepatic and renal transplantation. Lancet 1987;2: 474-475.

35. Broyer M, Brunner F, Brynger M, et al. Kidney transplantation in primary oxalosis: data from the EDTA Registry. Nephrol Dial Transplant 1990;5(5): 332336.

36. Gerber D, Hasegawa T, Mazariegos G. Oxalosis: stratifying disease severity and the role of organ transplantation. Transplantation 1998;65(12):S53.

Recibido: 10/11/04

Aceptado para publicación: 21/03/05 